Article

\title{
Separation and Identification of 1,2,4-Trihydroxynaphthalene- 1-O-glucoside in Impatiens glandulifera Royle
}

\author{
Jan Tř́ska ${ }^{1, *}$, Naděžda Vrchotová ${ }^{1}$, Jan Sýkora ${ }^{2}$ and Martin Moos ${ }^{1}$ \\ 1 Laboratory of Metabolomics and Isotopic Analyses, Global Change Research Centre, \\ Academy of Sciences of the Czech Republic, Branišovská 31, České Budějovice 37005 , \\ Czech Republic; E-Mails: vrchotova.n@czechglobe.cz (N.V.); moos.m@czechglobe.cz (M.M.) \\ 2 Department of Organic Synthesis and Analytical Chemistry, \\ Institute of Chemical Process Fundamentals, Academy of Sciences of the Czech Republic, \\ Rozvojová 135, Praha 165 05, Czech Republic; E-Mail: Sykora@icpf.cas.cz \\ * Author to whom correspondence should be addressed; E-Mail: triska.j@czechglobe.cz; \\ Tel.: +420-387-775-619; Fax: +420-385-310-347.
}

Received: 24 May 2013; in revised form: 10 July 2013 / Accepted: 10 July 2013 / Published: 17 July 2013

\begin{abstract}
Methanolic extract from lyophilized roots of Impatiens glandulifera Royle was analyzed by high performance liquid chromatography using DAD and FLD detection and this revealed one dominant highly fluorescent very unstable substance. The stability of this derivative is strongly dependent on the plant material drying procedure and extraction procedure used. The structure of the substance was established as 1,2,4trihydroxynaphthalene-1-O-glucoside (THNG) according LC-MS and NMR measurements. When lyophilized plant material was extracted with methanol an almost four times higher amount of THNG was found in the extract, compared to the amount of 2-hydroxy-1,4naphthoquinone obtained, while in the case of the same lyophilized plant material extracted with water there was no THNG in the extract. The main compounds in this case was 2-hydroxy-1,4-naphthoquinone. In the plant material dried at the laboratory temperature and extracted by methanol there are only traces of THNG.
\end{abstract}

Keywords: 1,2,4-trihydroxynaphthalene-1-O-glucoside; Impatients glandulifera Royle 


\section{Introduction}

Three species of Impatiens grow in Europe: Impatiens noli-tangere L., Impatiens glandulifera Royle and Impatiens parviflora DC. Impatiens noli-tangere L. is the original plant species, while Impatiens glandulifera Royle and Impatiens parviflora DC. are among the invasive plants originally native to Asia that are rapidly spreading across the Europe. The abovementioned Impatiens species also contain naphthoquinones in addition to phenolic compounds of the flavonol and caffeic acid type derivatives [1,2]. Naphthoquinones are contained predominantly in the roots and consist mainly of 2-hydroxy-1,4-naphthoquinone (lawsone) and 2-methoxy-1,4-naphthoquinone (lawsone methyl ether). Lawsone from Lawsonia inermis L. is still object of the research due to its various usages [3]. The first attempt to describe a trihydroxynaphthalene-glucoside in Impatiens species without location of glucose position was done by [4]. There are more information about trihydroxynaphthalene- $O$-glucosides in other plant species which contain the naphthoquinones, for examples: 1,2,4-trihydroxynaphthalene1,4-di- $\beta$-D-glucopyranoside in Lawsonia inermis L. [5], THNG was found for the first time in $n$-butanolic fraction of Lawsonia inermis L. [6], 7-methyl-1,4,5-trihydroxynaphthalene-4-O-glucoside in Drosera spathulata Labill. [7], 1,4,5-trihydroxynaphthalene-glucoside in Carya illinoensis (Wangenh.) K. Koch [8], several trihydroxynaphthalene glucosides were described in Juglans mandshurica Maxim. [9].

2-Hydroxy-1,4-naphthoquinone and 5-hydroxy-1,4-naphthoquinone were glucosidized and their acetylated glucosides were tested for their immunosuppressive and immunostimulative properties. It was found that their activity was comparable with clinically used preparation [10]. Naphthoquinones as aglycones have a wide range of biological properties, they are known for their phytotoxicity, extracts from Impatiens noli-tangere L., Impatiens glandulifera Royle and Impatiens parviflora DC. strongly inhibit the germination and growth [11]. Naphthoquinones from Drosera rotundifolia L. are used in respiratory difficulties [12]. In experiments on tobacco BY-2 cells naphthoquinones play a role in the cell death [13]. 2-Methoxy-1,4-naphthoquinone has strong in vitro anticancer activity against HepG2 cells, experiments that were performed with extracts from Impatients balsamina L. [14].

Due to long-term investigation of the biologically active substances in Impatients we found that the extract composition varies depending on the type of processing the plant material is subjected to. First, the plant material (roots) was air dried at the room temperature, which corresponds to the recent literature data about drying [6], where in the roots the dominant compound was 2-hydroxy-1,4naphthoquinone. THNG was not found in this case. In the subsequent lyophilization one dominant peak of a yet unknown substance appeared. Considering these facts, the main objective of our work was to study the conditions of plant material processing with respect to the maximum yield of this unknown substance.

\section{Results and Discussion}

For impatiens, we found that chromatographic profile of the extracts varies greatly depending on the method of plant material processing and its time of collection (Figures 1 and 2). 
Figure 1. The chromatographic profile (HPLC) of methanolic extracts prepared from the roots of Impatiens glandulifera Royle dried at room temperature (A) and lyophilized roots (B).

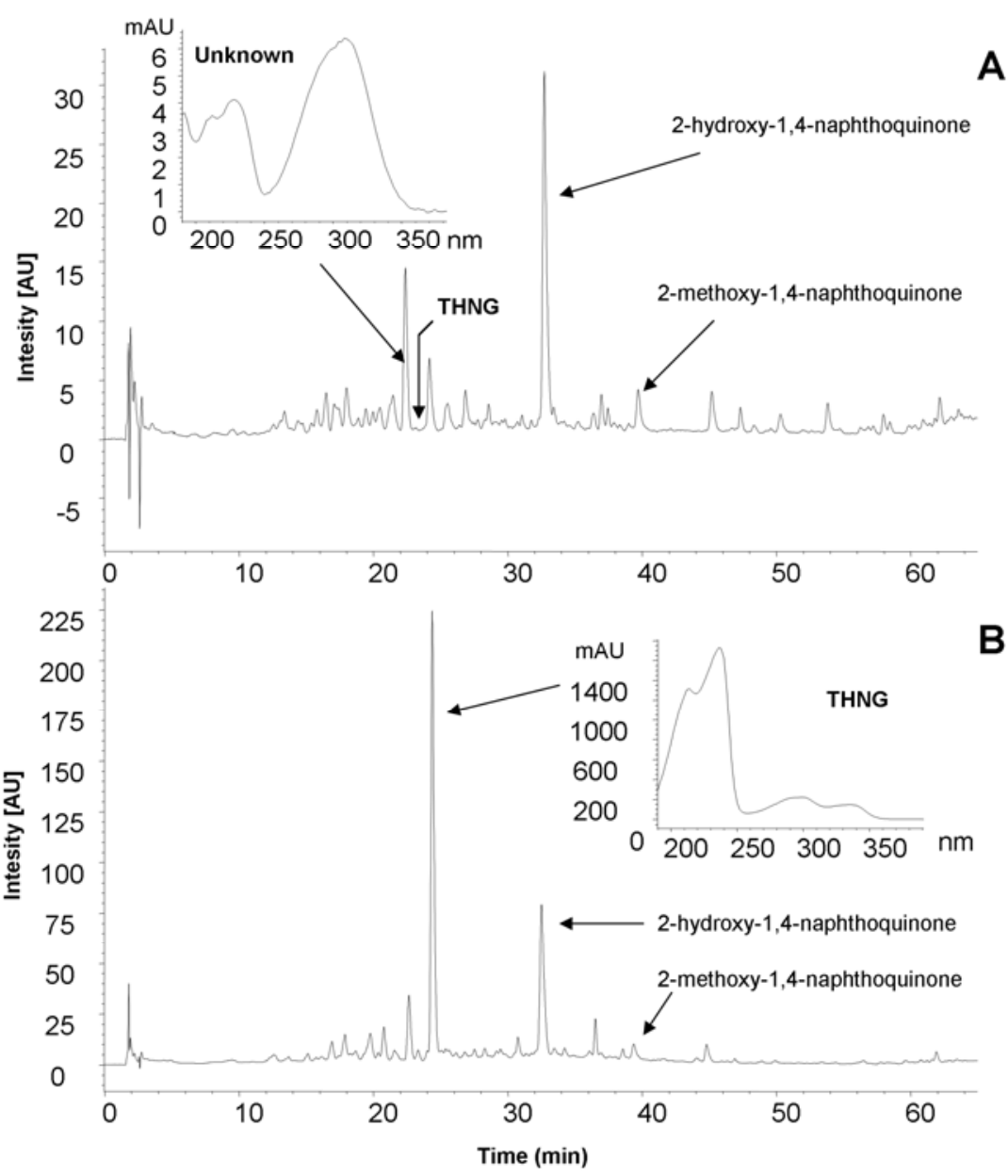

Figure 2. Chromatographic profile of the Impatiens glandulifera Royle methanolic extract of the roots measured as total ion current (TIC) by LC-MS (APCI). MS spectrum of THNG is shown on the Figure 3.

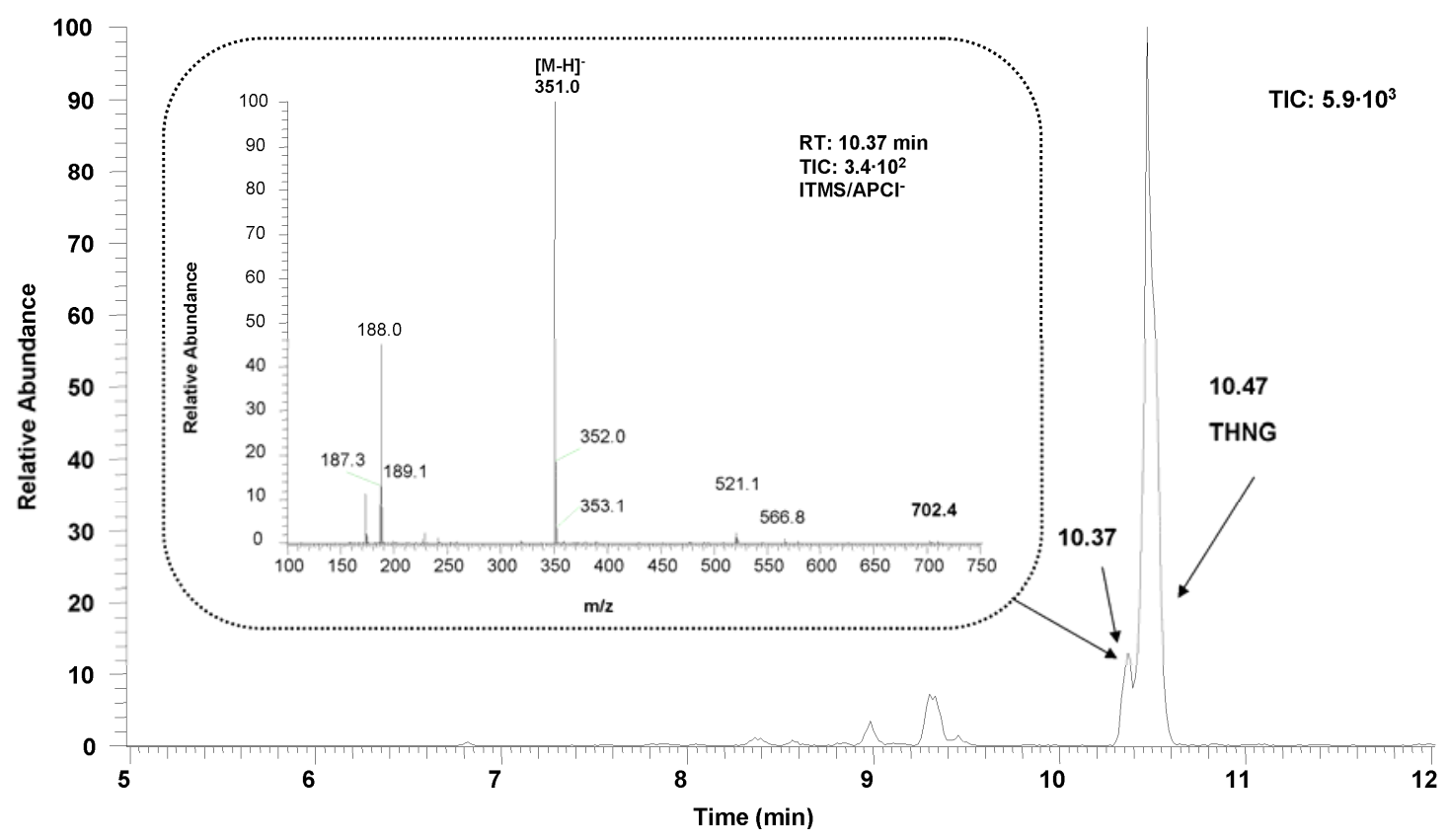


In the methanolic extracts from lyophilized roots of Impatiens glandulifera Royle we detected by liquid chromatography a dominant substance whose UV spectrum is different from that of the very common 2-hydroxy-1,4-naphthoquinone (the chromatographic profiles of the extracts are given in Figures 1 and 2) and which has a high fluorescence. The mass spectrum of the dominant substance was measured by LC-MS APCI in the negative mode (Figure 3). The molecular ion is $\mathrm{m} / z 337^{+}$(APCI negative mode) and the most significant fragment in the mass spectra (APCI negative mode) is $\mathrm{m} / \mathrm{z}$ $175^{+}[\mathrm{M}-162]^{+}$. A loss of $162 \mathrm{amu}$ corresponds to anhydroglucose and it is typical for the fragmentation of glucosides. Therefore the compound with the retention time $10.47 \mathrm{~min}$ (see Figures 2 and 3) was determined as trihydroxynaphthalene glucoside.

Figure 3. Mass spectrum and chemical structure of the 1,2,4-trihydroxynaphthalene-1-O-glucoside.

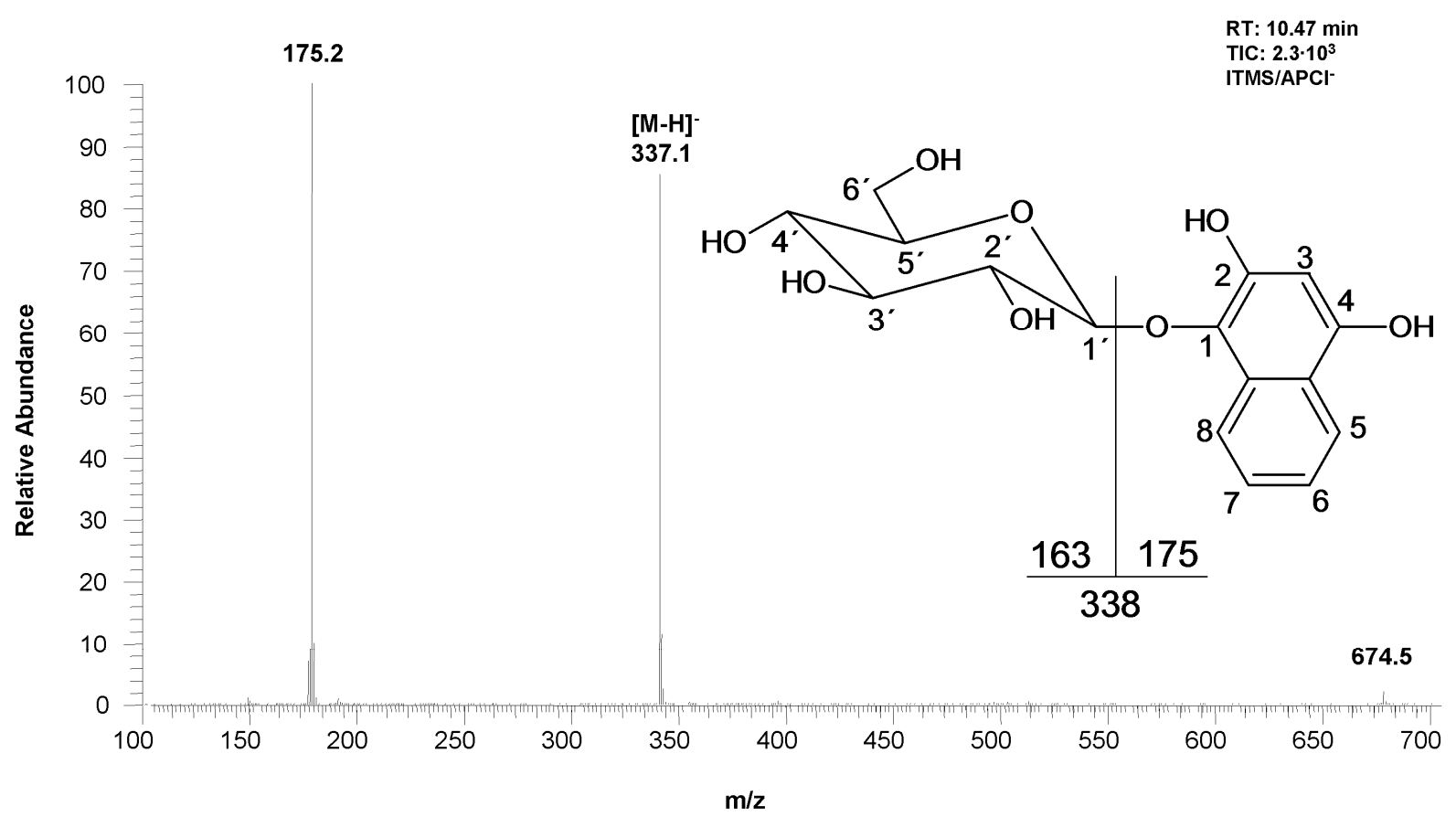

Identification of glucose, location of hydroxy groups and binding site of glucose was determined by NMR. The structure of the aglycone was also verified by NMR (Figure 4). Using NMR, it was established that the hydroxy groups are in position 1,2,4 and glucose is linked at position 1 (i.e., the structure is 1,2,4-trihydroxynaphthalene-1-O-glucoside, THNG). The structure elucidation was based on 2D experiments (COSY, HSQC and HMBC), given in Figure 5. Particularly this spectrum documents the concentration of the compound in the sample and its purity.

According to the literature THNG was recently found in an $n$-butanolic fraction of Lawsonia inermis L. [6]. It is interesting that in the literature relating to the compounds found in Impatiens species there is no mention of 1,2,4-trihydroxynaphthalene-1-O-glucoside (THNG) [4]. We believe that this fact is related to its very low stability. It is our opinion that the drying procedure and extraction method play a very important role in this fact. 
Figure 4. ${ }^{1} \mathrm{H}-\mathrm{NMR}$ spectrum and the signal assignment of 1,2,4-trihydroxynaphthalene-1-O-glucoside.

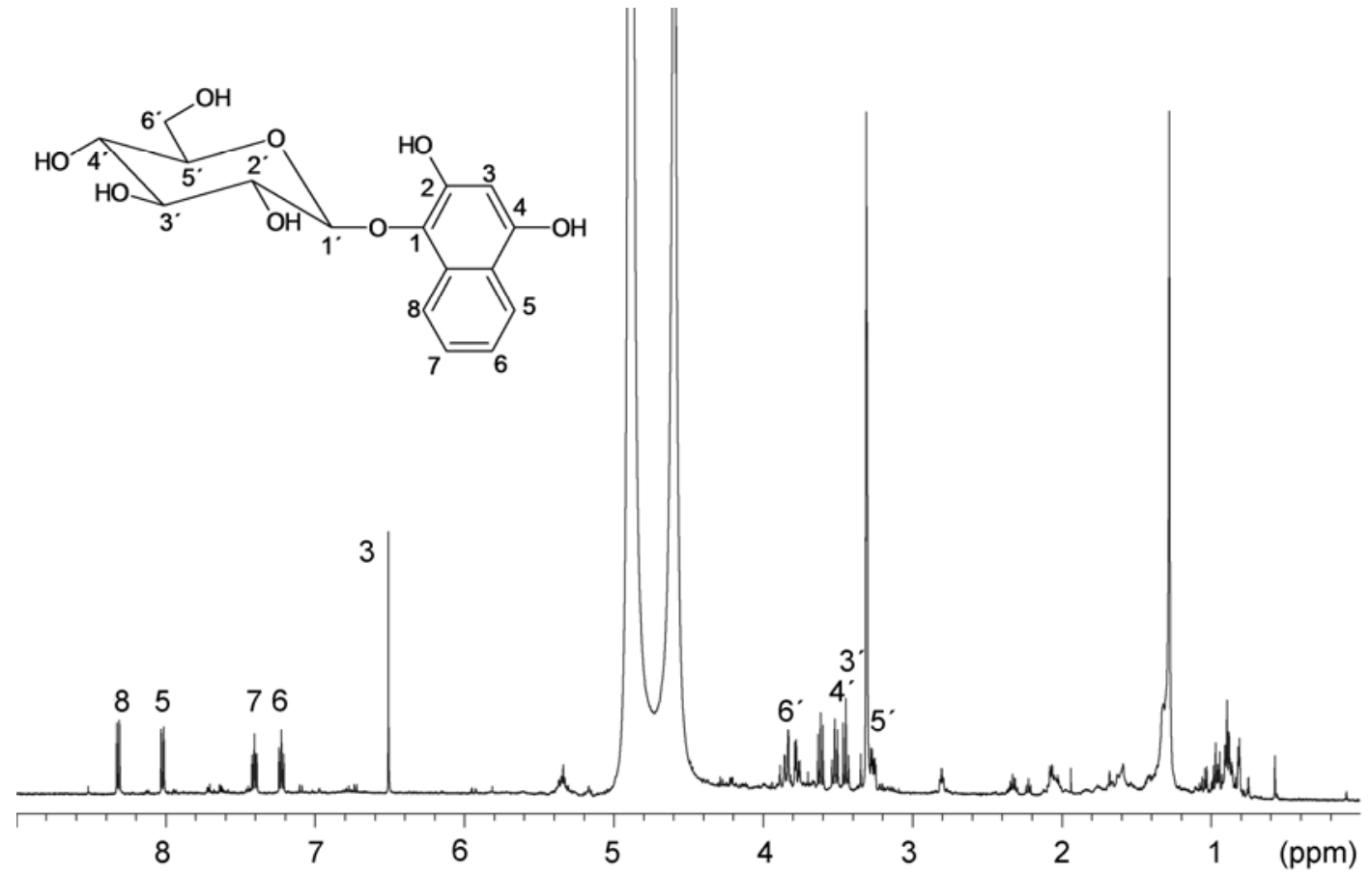

Figure 5. HSQC spectrum and the signal assignment of 1,2,4-trihydroxynaphthalene-1- $O$-glucoside.

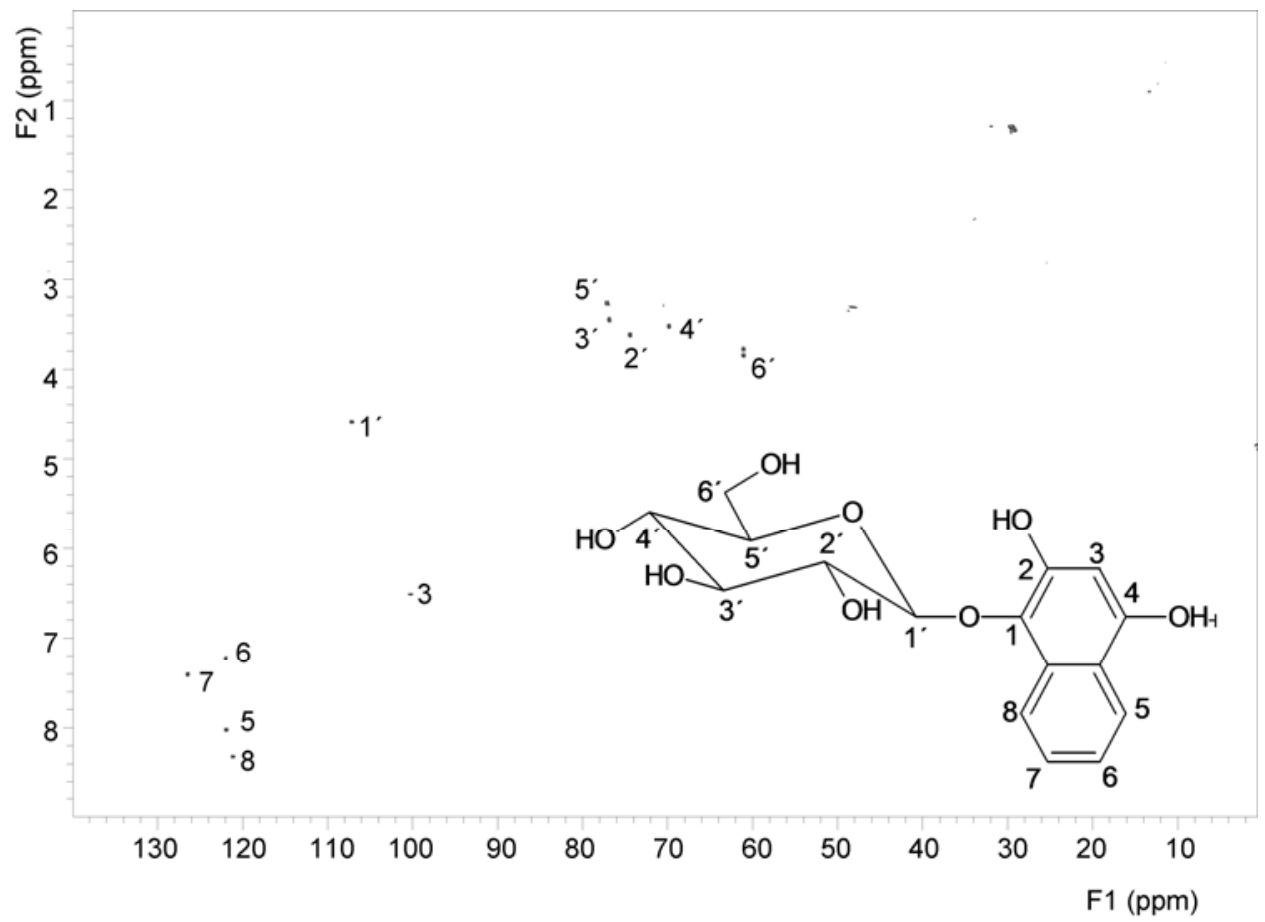

THNG can be determined in the methanolic extract of freeze-dried material even after several years, while in the material dried at room temperature there were practically only traces of THNG (Table 1). The solvent used for the extraction also affects the content of THNG. Extraction with water is more suitable for obtaining of 2-hydroxy-1,4-naphthoquinone and 2-methoxy-1,4-naphthoquinone, but THNG is practically not present in the aqueous fraction, although it is more polar than the naphthoquinones (Table 2). THNG was not detected even after subsequent extraction of the material 
with methanol. The results revealed that the originally present THNG is hydrolyzed to 1,2,4trihydroxynaphthalene (THN) by $\beta$-glucosidases, finally yielding 2-hydroxy-1,4-naphthoquinone (lawsone) according to Scheme 1. The intermediate aglycone THN is rather unstable, e.g., after mild acidic hydrolysis of THNG we did not find any trace of THN. The instability of THN is also supported by the literature [15]. The low stability of the aqueous extracts of 7-methyl-1,4,5trihydroxynaphthalene-4-O-glucoside (from Drosera) also points this out [7].

Table 1. The content of 1,2,4-trihydroxy-naphthalene-1-O-glucoside (THNG), 2-hydroxy1,4-naphthoquinone (A) and 2-methoxy-1,4-naphthoquinone (B) in Impatiens glandulifera Royle $(\mathrm{mg} / \mathrm{kg})$.

\begin{tabular}{cccccccc}
\hline Year of collection & Part of plant & Drying & Storage & Solvents & THNG & A & B \\
\hline 2008 & root & $\mathrm{RT}$ & $\mathrm{RT}$ & $\mathrm{MeOH}$ & $\mathrm{ND}$ & 48 & 8 \\
2008 & root & $-18{ }^{\circ} \mathrm{C}+\mathrm{LY}$ & $\mathrm{RT}$ & $\mathrm{MeOH}$ & 204 & 92 & 13 \\
2008 & root & $-18^{\circ} \mathrm{C}+\mathrm{LY}$ & $4{ }^{\circ} \mathrm{C}$ & $\mathrm{MeOH}$ & 210 & 115 & 7 \\
2011 & stem & $40{ }^{\circ} \mathrm{C}$ & $\mathrm{RT}$ & $\mathrm{MeOH}$ & 2 & 53 & 19 \\
2011 & stem & $-18{ }^{\circ} \mathrm{C}+\mathrm{LY}$ & $\mathrm{RT}$ & $\mathrm{MeOH}$ & 148 & 74 & 11 \\
2011 & stem & $-18{ }^{\circ} \mathrm{C}+\mathrm{LY}$ & $4{ }^{\circ} \mathrm{C}$ & $\mathrm{MeOH}$ & 176 & 70 & 10 \\
2011 & stem & $-18{ }^{\circ} \mathrm{C}+\mathrm{LY}$ & $-18^{\circ} \mathrm{C}$ & $\mathrm{MeOH}$ & 200 & 118 & 15 \\
2011 & root & $-18^{\circ} \mathrm{C}+\mathrm{LY}$ & $-18^{\circ} \mathrm{C}$ & $\mathrm{MeOH}$ & 826 & 143 & 51 \\
2011 & leaf & $-18^{\circ} \mathrm{C}+\mathrm{LY}$ & $-18{ }^{\circ} \mathrm{C}$ & $\mathrm{MeOH}$ & 247 & $\mathrm{ND}$ & 69 \\
2013 & leaf & $\mathrm{N}_{2}(1)+\mathrm{LY}$ & $\mathrm{WS}$ & $\mathrm{MeOH}$ & 230 & $\mathrm{ND}$ & 111 \\
2013 & stem & $\mathrm{N}_{2}(1)+\mathrm{LY}$ & $\mathrm{WS}$ & $\mathrm{MeOH}$ & 202 & 148 & 20 \\
2013 & root & $\mathrm{N}_{2}(1)+\mathrm{LY}$ & $\mathrm{WS}$ & $\mathrm{MeOH}$ & 1359 & 115 & 29 \\
2013 & leaf & $\mathrm{N}_{2}(1)+\mathrm{LY}$ & $\mathrm{WS}$ & $\mathrm{H}_{2} \mathrm{O}$ & $\mathrm{ND}$ & 499 & 1301 \\
2013 & stem & $\mathrm{N}_{2}(1)+\mathrm{LY}$ & $\mathrm{WS}$ & $\mathrm{H}_{2} \mathrm{O}$ & $\mathrm{ND}$ & 356 & 58 \\
2013 & root & $\mathrm{N}_{2}(1)+\mathrm{LY}$ & $\mathrm{WS}$ & $\mathrm{H}_{2} \mathrm{O}$ & 98 & 2277 & 81 \\
\hline
\end{tabular}

RT: room temperature; $-18{ }^{\circ} \mathrm{C}+\mathrm{LY}$ : frozen in a freezer at $-18{ }^{\circ} \mathrm{C}+$ lyophilization; $\mathrm{N}_{2}(1)+\mathrm{LY}$ : frozen in liquid nitrogen and lyophilization; WS: without storage; ND: below detection limit.

Table 2. The content of 1,2,4-trihydroxynaphthalene-1-O-glucoside (THNG), 2-hydroxy1,4-naphthoquinone (A) and 2-methoxy-1,4-naphthoquinone (B) in Impatiens glandulifera Royle (mg/kg) after subsequent extraction (water followed by methanol).

\begin{tabular}{|c|c|c|c|c|c|c|c|c|c|}
\hline \multirow[b]{2}{*}{ Year of collection } & \multirow[b]{2}{*}{ Part of plant } & \multirow[b]{2}{*}{ Drying } & \multirow[b]{2}{*}{ Storage } & \multicolumn{2}{|c|}{ THNG } & \multicolumn{2}{|c|}{$\mathbf{A}$} & \multicolumn{2}{|c|}{ B } \\
\hline & & & & $\mathrm{H}_{2} \mathrm{O}$ & МeOH & $\mathrm{H}_{2} \mathrm{O}$ & МеОН & $\mathrm{H}_{2} \mathrm{O}$ & МeOH \\
\hline 2008 & root & RT & RT & ND & ND & 46 & 16 & 4 & 1 \\
\hline 2008 & root & LY & RT & $\mathrm{ND}$ & ND & 740 & 335 & 17 & 23 \\
\hline 2008 & root & LY & $4^{\circ} \mathrm{C}$ & $\mathrm{ND}$ & ND & 1121 & 484 & 15 & 20 \\
\hline 2011 & stem & $40^{\circ} \mathrm{C}$ & RT & ND & ND & 128 & 47 & ND & ND \\
\hline 2011 & stem & LY & $\mathrm{RT}$ & $\mathrm{ND}$ & ND & 321 & 235 & 43 & 25 \\
\hline 2011 & stem & LY & $4^{\circ} \mathrm{C}$ & $\mathrm{ND}$ & ND & 263 & 177 & 48 & 24 \\
\hline 2011 & stem & LY & $-18^{\circ} \mathrm{C}$ & ND & ND & 319 & 191 & 54 & 24 \\
\hline
\end{tabular}

RT: room temperature; LY: lyophilization; ND: below detection limit. 
Scheme 1. Transformation of 1,2,4-trihydroxynaphthalene-1-O-glucoside to 2-hydroxy-1,4-naphthoquinone (lawsone).

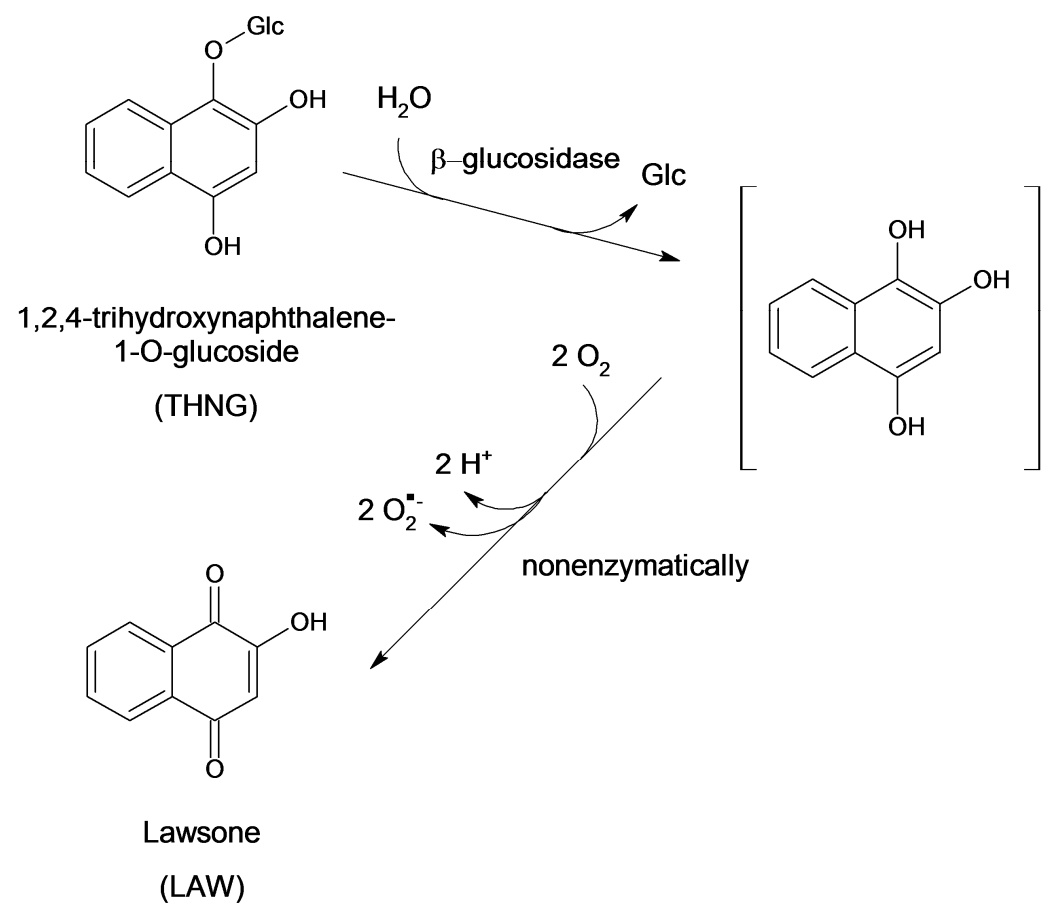

We found that THNG is contained not only in the roots, but in lesser amounts also in aboveground parts of Impatiens glandulifera Royle. Figure 6 shows chromatogram of the methanolic extract of fresh flowers and fluorescence spectra of THNG and unknown compound.

Figure 6. HPLC chromatographic profile of the fresh flower methanolic extract of Impatiens glandulifera Royle with FLD detection.

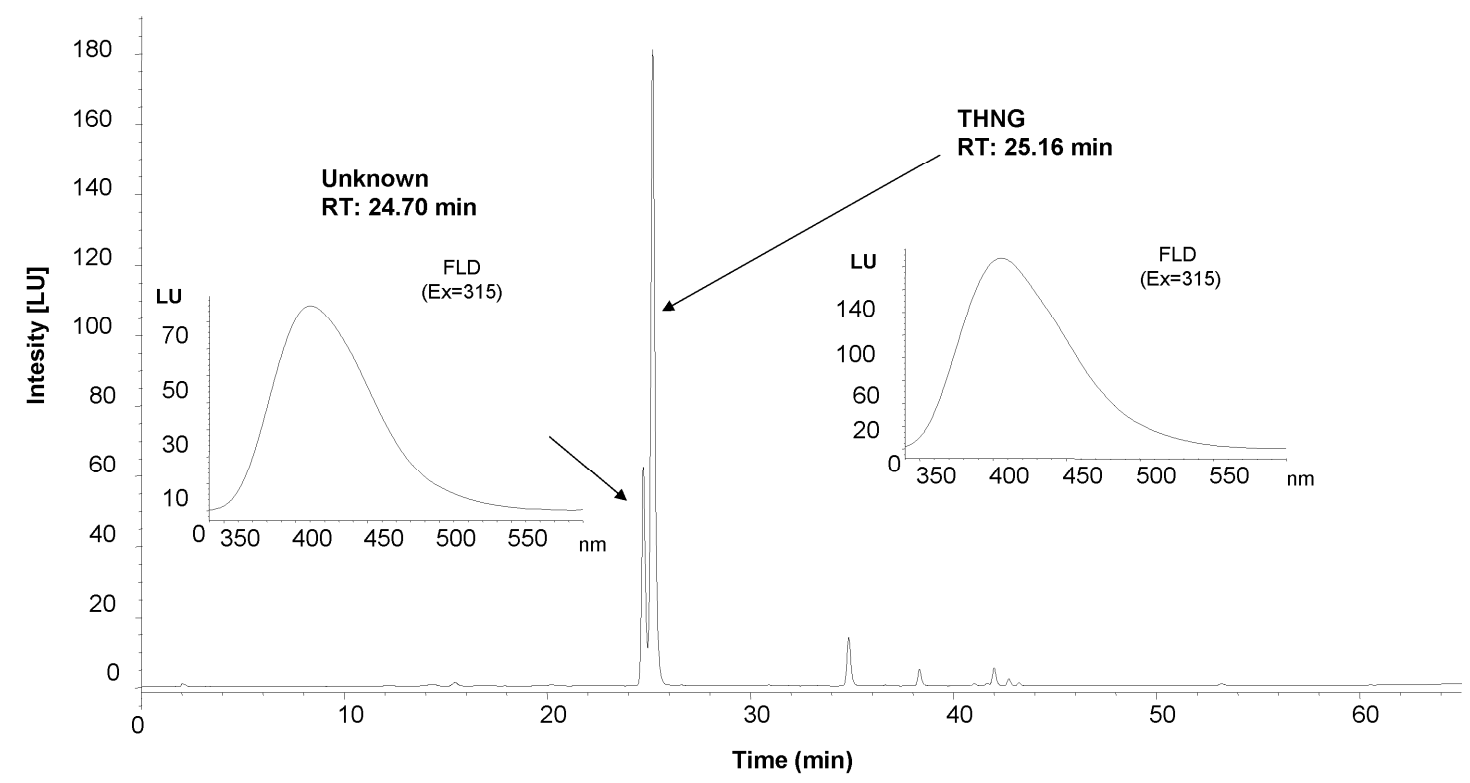

The spectra are very similar, there is only shift in the maximum $(+3 \mathrm{~nm}$ for the unknown compound compare to THNG). In addition, we have found besides THNG in the lyophilized or fresh materials of Impatiens other substances that have similar UV and FLD spectrum as THNG; the mass spectrum this 
compound is shown in Figure 2. The compound was found in Impatients parviflora DC. and Impatients balsamina L., not only in the roots, but also in the above-ground parts of the plants. In the roots of Impatiens glandulifera Royle we also identified scopoletin, which has been previously described in root cultures of Impatiens balsamina L. [16].

\section{Experimental}

\subsection{Standards}

Both 2-hydroxy-1,4-naphthoquinone and 2-methoxy-1,4-naphthoquinone were purchased from the Extrasynthese Lyon Nord, Genay Cedex, France.

\subsection{Sample Preparation}

Impatiens glandulifera Royle and Impatiens parviflora DC. plants were collected around Ceske Budejovice. A large number of plants (at least 5) has always been sampled at one location to ensure homogeneity of the material. Impatiens balsamina L. was purchased in a local shop. It was a pink variety $\mathrm{K} 11$. The material was divided into roots, stems and leaves, and cut into smaller pieces of about $10 \mathrm{~cm}$. The plant material was dried under various conditions: at room temperature, at $40{ }^{\circ} \mathrm{C}$ and it was also lyophilized (plant material was frozen at $-18{ }^{\circ} \mathrm{C}$ before lyophilization). After drying, the material was finely shredded using knife grinder, mixed thoroughly and kept at different temperatures $\left(-18{ }^{\circ} \mathrm{C},+4{ }^{\circ} \mathrm{C}\right.$ and laboratory temperature). The extracts from materials collected in years 2008 and 2011 were prepared in 2011. The flowers were immediately immersed in methanol after being picked at the sampling site. In 2013, the plant material was immediately immersed into liquid nitrogen directly at the sampling site and after transportation to the laboratory and after removal from liquid nitrogen the samples were immediately placed in a freeze drier. After lyophilization the samples were immediately grinded up and extracted.

Plant materials were extracted by several ways:

1) Extraction with $100 \%$ methanol for $30 \mathrm{~min}$ at the room temperature under continuous shaking, after centrifugation the sediment was washed further twice with methanol and the supernatants were combined.

2) Extraction with distilled water under the same conditions as with methanol and after centrifugation the sediment was washed twice with water, supernatants were combined, then the sediment was extracted with methanol for $30 \mathrm{~min}$ at the room temperature under continuous shaking, the sediment after centrifugation was washed twice with methanol and methanolic extracts were combined (Table 2).

3) For NMR measurements the lyophilized roots were not extracted with methanol, but with ethyl acetate. Ethyl acetate fraction was then evaporated in a vacuum evaporator to dryness and the sample was dissolved in small volume of methanol. Extraction with ethyl acetate is not as effective as extraction with methanol, but the resulting extract is relatively clean, containing only a minor impurities. During the extraction with ethyl acetate very polar compounds and free sugars do not pass into extract. After evaporation of the ethyl acetate and dissolution of the residue in a small amount of methanol (the mixture must be filtrated or centrifuged) we will obtain the extract which 
is almost free from non polar compounds, e.g., lipids, sterols, etc. Before NMR measurements the methanol was evaporated and the sample was dissolved in deuterochloroform.

\subsection{Samples Analysis}

\subsubsection{HPLC Analysis}

The samples were analyzed using an HP 1050 (Ti-series) HPLC instrument (Hewlett Packard, Palo Alto, CA, USA) on column Luna C18(2) (Phenomenex, Torrance, CA, USA) $3 \mu \mathrm{m}, 150 \mathrm{~mm} \times 2 \mathrm{~mm}$, with water-acetonitrile- $O$-phosphoric acid mobile phase. Mobile phase A: $5 \%$ acetonitrile $+0.1 \%$ $O$-phosphoric acid; mobile phase B: $80 \%$ acetonitrile $+0.1 \% o$-phosphoric acid. The gradient was increased from $0 \% \mathrm{~B}$ to $45 \% \mathrm{~B}$ during $55 \mathrm{~min}$ and than from $45 \% \mathrm{~B}$ to $80 \% \mathrm{~B}$ during $10 \mathrm{~min}$. Flow rate was $0.250 \mathrm{~mL} / \mathrm{min}$ and column temperature $25{ }^{\circ} \mathrm{C}$. Injection volume was $5 \mu \mathrm{L}$. Diode array detector HP G1315B (DAD, Hewlett-Packard) was used and compounds were detected at 220 and $228 \mathrm{~nm}$. Scanning was carried out in range 190-600 nm. Fluorescence detector HP G1321A (FLD, Hewlett-Packard) was used, with excitation wavelength $315 \mathrm{~nm}$, emission wavelength $395 \mathrm{~nm}$, and scanning of emission was carried out in the range of 300-600 nm. Finally, the method was validated in terms of linearity, limits of detection [17], and repeatability, and it was applied to the analysis of all extracts samples. Detection limit for 2-hydroxy-1,4-naphthoquinone was $0.0018 \mu \mathrm{g} / \mathrm{mL}$ and for 2-methoxy-1,4-naphthoquinone was $0.0016 \mu \mathrm{g} / \mathrm{mL}$. The content of THNG was calculated according to calibration curve for 2-hydroxy-1,4-naphthoquinone.

\subsubsection{LC-MS Analysis}

LC-MS was performed using LCQ Accela Fleet (Thermo Fisher Scientific, San Jose, CA, USA) with atmospheric pressure chemical (APCI) and a photodiode array detector. A Phenomenex Luna C18(2) column $3 \mu \mathrm{m}, 150 \mathrm{~mm} \times 2 \mathrm{~mm}, 18(2)$ column was used with a water-acetonitrile-formic acid mobile phase. Mobile phase A $5 \%$ acetonitrile $+0.1 \%$ formic acid; mobile phase B used $80 \%$ acetonitrile $+0.1 \%$ formic acid. The gradient was increased from $0 \% \mathrm{~B}$ to $45 \% \mathrm{~B}$ during $20 \mathrm{~min}$ and from $45 \% \mathrm{~B}$ to $70 \mathrm{~B}$ during $5 \mathrm{~min}$. Flow rate was $0.250 \mathrm{~mL} \mathrm{~min}^{-1}$. Injection volume was $5 \mu \mathrm{L}$. APCI capillary temperature was $275^{\circ} \mathrm{C}$, APCI vaporizer temperature $450{ }^{\circ} \mathrm{C}$, sheath gas flow $50 \mathrm{~L} \mathrm{~min}^{-1}$, auxiliary gas flow $5 \mathrm{~L} \mathrm{~min}^{-1}$, source voltage $6 \mathrm{kV}$, source current $5 \mu \mathrm{A}$, and capillary voltage $-4 \mathrm{~V}$. Methanolic extract of Impatiens glandulifera root was diluted 1:2 with methanol and than 1:1 with deionized water before measurement.

\subsubsection{NMR measurement}

${ }^{1} \mathrm{H}$ - and ${ }^{13} \mathrm{C}-\mathrm{NMR}$ measurements were performed on Varian INOVA $500 \mathrm{MHz}$ spectrometer equipped with standard broadband probe at $25{ }^{\circ} \mathrm{C}$. The structure elucidation was based on $2 \mathrm{D}$ experiments (COSY, HSQC, HMBC). The NMR spectra were referenced to the solvent signal: 3.34 and $47.85 \mathrm{ppm}$ for ${ }^{1} \mathrm{H}$ and ${ }^{13} \mathrm{C}$, respectively. The obtained shifts are as follows: ${ }^{1} \mathrm{H}-\mathrm{NMR}\left(\mathrm{CD}_{3} \mathrm{OD}\right): \delta$ (ppm) 8.35 (d, 1H, H-8), 8.05 (d, 1H, H-5), 7.44 (dt, 1H, H-7), 7.26 (dt, 1H, H-6), 6.54 (s, 1H, H-3), $4.62\left(\mathrm{~d}, 1 \mathrm{H}, \mathrm{H}-1^{\prime}\right), 3.88$ (dd, 1H, H-6a'), 3.80 (dd, 1H, H-6b'), 3.65 (t, 1H, H-2'), 3.55 (t, 1H, H-4'), $3.48\left(\mathrm{t}, 1 \mathrm{H}, \mathrm{H}-3^{\prime}\right), 3.30\left(\mathrm{~m}, 1 \mathrm{H}, \mathrm{H}-5^{\prime}\right) .{ }^{13} \mathrm{C}-\mathrm{NMR}\left(\mathrm{CD}_{3} \mathrm{OD}\right): \delta(\mathrm{ppm}) 151.4\left(\mathrm{C}_{\mathrm{q}}-\mathrm{OH}, \mathrm{C}-4\right), 146.5$ 
( $\left.\mathrm{C}_{\mathrm{q}}-\mathrm{OH}, \mathrm{C}-2\right), 131.2$ ( $\left.\mathrm{C}_{\mathrm{q}}-\mathrm{OGlyc}, \mathrm{C}-1\right), 129.8\left(\mathrm{C}_{\mathrm{q}}, \mathrm{C}-9\right), 126.4(\mathrm{CH}, \mathrm{C}-7), 121.9$ (2xCH, C-5,6), 121.1 (CH, C-8), 120.5 (C $\left.\mathrm{C}_{\mathrm{q}}, \mathrm{C}-10\right), 107.1$ (CH-ONaph, C-1'), $100.2(\mathrm{CH}, \mathrm{C}-3), 77.1\left(\mathrm{CH}, \mathrm{C}-5^{\prime}\right), 76.9(\mathrm{CH}$, C-3'), $74.4\left(\mathrm{CH}, \mathrm{C}-2^{\prime}\right), 69.8\left(\mathrm{CH}, \mathrm{C}-4^{\prime}\right), 61.0\left(\mathrm{CH}_{2}, \mathrm{C}-6^{\prime}\right)$.

\section{Conclusions}

This work demonstrates the presence and identification of an unstable fluorescent compound which is present in all parts of the Impatients glandulifera Royle plants. The possibility of isolation of the compound depend on the drying conditions, storage conditions and on the extraction process. Very clean extract was obtained by the extraction of plant material with ethyl acetate. The structure of compound was assigned as 1,2,4-trihydroxynaphthalene-1-O-glucoside according to LC-MS and NMR measurements. The lyophilized roots of Impatients glandulifera Royle plant contain up to $826 \mathrm{mg} / \mathrm{kg}$ of this compounds when the roots were stored at $-18{ }^{\circ} \mathrm{C}$ and extracted with methanol, while in the case of the same lyophilized plant material extracted with water as the first solvent, there is no glycoside in the extract. The main compound in this case is 2-hydroxy-1,4-naphthoquinone as a final transformation product of the above newly identified compound. 1,2,4-Trihydroxynaphthalene-1-O-glucoside was identified for the first time as a main fluorescent compound in the roots and stems of Impatients glandulifera Royle plants. Impatients glandulifera Royle contains appreciable amounts of 2-methoxy1,4-naphthoquinone, the plant is easily accessible and provides a large amount of plant material, it could serve therefore as a source of naphthoquinones. An open question is still the role of THNG in the plants.

\section{Acknowledgements}

This study was funded by the Grant Agency of the Ministry of Education, Youth and Sports of the Czech Republic, COST FP0901, No. LD11014 and by CzechGlobe - Centre for Global Climate Change Impacts Studies, Reg. No. CZ.1.05/1.1.00/02.0073. Thanks are also due to Božena Šerá for her help in the collection of the plants materials.

\section{Conflict of Interest}

The authors declare no conflict of interest.

\section{References}

1. Lobstein, A.; Brenne, X.; Feist, E.; Metz, N.; Weniger, B.; Anton, R. Quantitative determination of naphthoquinones of Impatiens species. Phytochem. Anal. 2001, 12, 202-205.

2. Šerá, B.; Vrchotová, N.; Tř́iska, J. Phenolic compounds in the leaves of alien and native Impatiens plants. In Proceedings of the Introduction and Spread of Invasive Species, Berlin, Germany, 9-11 June 2005.

3. Ashnagar, A.; Shiri, A. Isolation and characterization of 2-hydroxy-1,4-naphthoquinone (lawsone) from the powdered leaves of henna plant marketed in Ahwaz city of Iran. Int. J. ChemTech. Res. 2011, 3, 1941-1944. 
4. Vrchotová, N.; Tř́iska, J.; Jílek, R. Separation of quinones from the roots of Impatients glandulifera on the SPE columns. In Proceedings of the Italian meeting on lignocellulosic chemistry 6- Analytical Techniques for biorefineries, Viterbo, Italy, September 2011.

5. Takeda, Y.; Fatope, M.O. New phenolic glucosides from Lawsonia inermis. J. Nat. Prod. 1988, $51,725-729$.

6. Hsouna, A.B.; Trigui, M.; Culili, G.; Blafne, Y.; Jaoua, S. Antioxidant constituents from Lawsonia inermis leaves: Isolation, structure elucidation and antioxidative kapacity. Food Chem. 2011, 125, 193-200.

7. Budzianowski, J. Naphthoquinones of Drosera spathulate from in vitro culture. Phytochemistry 1995, 40, 1145-1148.

8. Hedin, P.A.; Collum, D.H.; Langhans, V.E.; Graves, C.H. Distribution of muflone and related compounds in pecan and their effect on Fusicladium effusum. J. Agric. Food Chem. 1980, 28, 340-342.

9. Son, J.K. Isolation and structure determination of a new tetralone glucoside from the roots of Juglans mandshurica. Arch. Pharm. Res. 1995, 18, 203-205.

10. Steinerová, N.; Cudlín, J.; Vaněk, Z. Glucosidation of 2-hydroxy- and 5-hydroxy-1,4naphthoquinone. Collect. Czech. Chem. Commun. 1980, 45, 2684-2687.

11. Babula, P.; Adam, V.; Kizek, R.; Sladký, Z.; Havel, L. Naphthoquinones as allelochemical triggers of programmed cell death. Environ. Exp. Bot. 2009, 65, 330-337.

12. Vrchotová, N.; Šerá, B.; Krejčová, J. Allelopathic activity of extracts from Impatients species. Plant Soil Environ. 2011, 57, 57-60.

13. Budzianowski, J. Naphthoquinone glucosides of Drosera gigantea from in vitro cultures. Planta Med. 2000, 66, 667-669.

14. Ding, Z.S.; Jiang, F.S.; Chen, N.P.; Lv, G.Y.; Zhu, Ch.G. Isolation and identification of an anti-tumor component from leaves of Impatiens balsamina. Molecules 2008, 13, 220-229.

15. Müller, U.; Lingens, F. Degradation of 1,4-naphthoquinones by Pseudomonas putida. Biol. Chem. Hoppe Seyler. 1988, 369, 1031-1043.

16. Panjchayupakaranant, P.; Noguchi, H.; De-Eknamkul, W., Sankawa, U. Naphthoquinones and coumarins from Impatiens balsamina root cultures. Phytochemistry 1995, 40, 1141-1143.

17. International Union of Pure and Applied Chemistry. Guidelines for data acquisition and data duality evaluation in environmental chemistry. Anal. Chem. 1980, 52, 2242-2249.

Sample Availability: Samples of the extracts are available from the authors.

(C) 2013 by the authors; licensee MDPI, Basel, Switzerland. This article is an open access article distributed under the terms and conditions of the Creative Commons Attribution license (http://creativecommons.org/licenses/by/3.0/). 